\title{
The impacts of Resource Development Projects on Community Livelihoods in Papua New Guinea: A Case Study From Mining and Agriculture Projects
}

\author{
Francis Essacu ${ }^{1}$
}

\begin{abstract}
The impacts of natural resource development projects have documented positive impacts on local communities, but there is much less evidence of long-term community impacts or benefits as development outcomes. Understanding these impacts of resource development projects on communities' livelihoods, stability and prosperity is fundamental to the achievement of sustainable development outcomes in rural communities in Papua New Guinea (PNG), as it plays an important role in the livelihoods of rural population. To explore the relationship between natural resourcebased development projects and community livelihoods capacity as sustainable development outcomes, an interview data from 90 participants in two provinces of PNG associated with resource projects were collected and analyzed. Community livelihoods impacts were assessed using Likert Scale and thematic network analysis to determine impacts on development outcomes on stability and prosperity in the community. The findings demonstrated that the scale and levels of impacts on communities in terms of livelihoods assets-bases, stability and prosperity; were reflective and indicative of the form and nature of development projects in the region, and the difference in development stages of natural resource projects in each of the regions.
\end{abstract}

Keywords: Natural resources projects, mining, agriculture, community livelihoods, sustainable development outcomes, stability, prosperity.

\section{Introduction}

Papua New Guinea (PNG) is a resource-rich developing nation with abundant natural resources and a relatively small population of about 8 million people (GoPNG 2011). The country is globally distinctive in many respects. The nation's customary land tenure systems are enshrined in the 1975 National Constitution, providing customary landowners with full rights over their traditional lands and natural resources, although these may be mediated in practice by government. PNG's economy is almost completely founded on natural resource-based development (Banks, 2008), which in turn depends on agreements between developers and customary landowners to access land and resources (Anderson, 2015). Correspondingly, customary landowners have expectations about the development outcomes that will result from allowing such access (Kepore and Imbun, 2011; Banks, 2003). This paper reports the results of research investigating impacts of natural resource-based developments on community livelihoods outcomes in a development context. It focuses on two resource projects and the subsequent stability and prosperity in the communities.

\footnotetext{
${ }^{1}$ Department of Communictaion \& Development Studies, Papua New Guinea University of Technology PMB, Lae, 411 Morobe Province, Papua New Guinea
} 
The two case study projects are inherently different, representing the mining and agriculture (oil palm) sectors respectively, and at different scales; and given the diverse environmental and social circumstances in PNG, there are also likely to be difference between the two development projects in terms of their impacts on communities. The Ok Tedi mine has been subject to much critique both internationally and PNG because of its ecological and social consequences along the Ok Tedi and Fly River systems (Kepore and Imbun, 2011). Similarly, the Oil palm development projects have also been contested in various debates on its adverse impacts on social and environmental issues in PNG and abroad (Koczberski, \& Curry, 2005). While there has been much discussion and critique about the Ok Tedi mine (see, e.g. Kepore and Imbun 2011), and oil palm development projects (Anderson, 2015; Koczberski, \& Curry, 2005), both projects remain very fundamental sources of income and improve livelihoods of communities at local levels.

\section{The Context of this study}

Given that over $85 \%$ of Papua New Guineans still live in rural communities in which 'natural resource bases remain important (AusAID, 2006; Bourke and Harwood, 2009), this research focuses on natural resource development projects and livelihoods. Natural Resources in this study refers to minerals, oil, gas, forests, and the land resources associated with customary ownership. These resources are the livelihoods base of rural PNG communities (Anderson, 2015; Koczberski, \& Curry, 2005). Internationally, natural resource-based development projects have been directed consciously towards sustainable development (Banks, 2008) and sustainable livelihood outcomes, and many studies have shown that appropriate natural resource development is particularly important for rural community livelihoods (Chambers \& Conway, 1991). In the mining sector also, there has been an increasing focus on sustainable community development projects as part of corporate social responsibility initiatives promoted in mine impact regions (Jackson, 2002; Scambary, 2013). More generally, the links between rural community, poverty alleviation and income from natural resources have been recognized by initiatives such as the Millennium Development Goals (MDGs) (Yemiru et al, 2010).

Natural Resource development projects play important roles in the lives of many rural based populaces, in terms of improvement of communities' livelihoods and the sustenance of identify and social relationship (Banks, 2008). It further enhances level of participation in development context when decisions about resource use, and decisions about the best way to share the benefits of development - e.g. through the distribution of royalties earned through resource development enterprises are made. Besides this, rural communities in PNG are also confronted with many issues fundamental to development and its outcomes. These sentiments are consistent with (Banks, 2008; 2003) observations that natural resource development based conflicts are imminent in PNG. Livelihoods, as defined by Chambers \& Conway (1991) and DIFD (1999) are competencies and abilities of rural populations to improve and develop their wellbeing. In PNG context, (Anderson, 2015) described livelihoods as peoples' socio-economic abilities that enhance their day-to-day lives in the villages. Through the analysis of (Anderson, 2015; Koczberski, \& Curry, 2005) livelihoods interpretations and that of 
DFID (1999) livelihoods framework analysis, one can recognize and relate that; the most significant elements of livelihoods in PNG are those assets relating to their cultures and traditions; social structures and relationships; natural capital resources such as land, forests and minerals; and economic infrastructure such as roads, logistics and markets.

Livelihood Assets are those assets on which community livelihoods are built, and are often categorized as: human, natural, financial, social, and physical (Chambers \& Conway, 1991; DFID, 1999). Communities' choice of their livelihood strategies and objectives, and the influence they have over certain strategies, institutional systems, depends somewhat upon the nature and types of the assets they have in their community (DFID, 1999). Drawing from these five livelihood assets and their definitions, the study assessed various assets defined under each of these five categories. For example, communities' skills and their abilities to perform various skilled jobs were assessed under human asset. All natural resources; including forest, land, clean air, fishery, water, coastal resources were assessed under natural assets. All savings, access to loans, wages and other entitlements, the availability of royalty, equity, compensation and grants payments made to the communities were categorized under financial assets. Those investments in relationships, networking and interactions (through work or shared interests) that increase people's levels of skills, learning and thinking abilities to work together were assessed under social asset. Finally, those assets that support the livelihoods of the community such as affordable transport systems, adequate water supply and sanitation; clean and affordable energy; improve communications; adequate and quality shelter and other productive capital that enhances income (e.g., vehicles, outboard motors, bicycles, agricultural equipment, household goods and utensils were categorized as strong physical capital assets.

\section{Research objectives and questions}

The overall objective of the study was to understand how natural resource projects were developed and their impacts on the livelihoods of the resource owing communities in PNG. To achieve the overall objective, two primary research questions were asked: (1) what were the natural resource developments types, their significance and livelihoods assets-bases, evident in the two study regions? (2) What were the impacts of these resource developments on the development outcomes in terms of stability and prosperity?

\section{Research approach and methodology}

The study was grounded in a theoretical framework which draws from two established frameworks; the Social Ecological Systems Framework (SESF) (Ostrom, 2009), and the Sustainable Livelihoods Framework (SLF) (Chambers and Conway, 1991; DFID, 1999). In particular, the SLF was used as a key framework to understand the impact natural resource development has on the community's livelihood assets. It was adopted purposely to understand the relationships between natural resource development and livelihood assets as the development outcomes. A case study approach (Yin, 2003) was adapted investigating through the research question in two provinces of PNG. Research data for this study was based on field survey conducted between July 
2011 and October 2012 that investigated natural resource development projects, a range of livelihoods parameters, and development outcomes (i.e. stability and prosperity). Primary data were derived from 90 household interviews in six communities across the two case study regions. A sample size of 20 participants was used in each of the selected case study units of analysis. A contingency plan was also considered to recruit additional participants beyond 20 in the event that theoretical data saturation stage was not achieved. In the actual survey, the contingency plan was not implemented because the theoretical data saturation point was achieved. The researcher was unable to find new data emerging after conducting 17 to 18 interviews in the case study communities.

In every community, before conducting household interviews, the researcher consulted with the local leaders to explain the purpose of the research and to seek approval to contact the members of the study communities. The local leaders agreed with the request and arrangements were made to meet with the members of the communities. During these community meetings the local leaders and senior community members assisted the researcher in selecting 20 households from their villages to be interviewed. Participants in the household survey were randomly selected by drawing their names from a box containing the name of all households in the community. This process was appropriate as the updated village or ward common rolls were available at the time of this study. This further helped to minimize any issues relating to bias that may have occurred if the researcher was just to hand picking the household participants. Secondary data were also gathered from personal communications with local and regional leaders and resource owners, and complemented by secondary published and unpublished sources. The data was analyzed using Likert Scale method (Uebersax 2006) analyzing the five key capital assets-bases and supported by thematic network process (Attride-Stirling 2001) for assessing stability and prosperity in the communities. The total households participated in each region were 47 in ENBP and 43 in WP. These participants were asked to assess strength and weaknesses of each of these assets by allocating an approximate score ranging from 1-5 (1 being the weakest and 5 being the strongest).

\section{Research findings}

The principal findings of the research in response to research questions above are presented in three parts. Part 1 basically describes the different natural resource development projects found and their significance in the two study regions. Part 2 presents the livelihood asset-bases in each study regions and Part 3 demonstrates the impacts of type of natural resource-based development projects on stability and prosperity in each of the study case regions.

\subsection{Case study projects and their significance}

This section provides the results of the research in response to first part of research question 1; viz. the different types of natural resource development projects their significance in the study regions. As briefly introduced in Section 1, two natural resource projects - one in each region - are at different stages of implementation in the case study regions. These projects are the Kairak Oil Palm Development Project (KOPDP) and the Ok Tedi Mining Limited (OTML) mine. 
The KOPDP is relatively new into its seventh year of operation. Consequently, there was limited data on current household livelihoods, impacts of proposed or recent changes and other development benefits. In contrast, OTML project has been one of the largest resource development projects in PNG for over 30 years, and has been a major contributor to the PNG economy, as well as to the socio-economic status of the people of Western Province. OTML has attracted much attention both nationally and internationally, largely because of the downstream environmental and social impacts of its operations.

\subsection{Results of livelihood asset bases in the case study regions}

This section presents the results of the research in response to second part of research question on livelihood assets-bases in the communities. Figures 1 and 2 provide a summary of the findings (i.e. strengths and weaknesses) about the livelihoods assetsbases across the two case study regions. This analysis was done by aggregating the proportions of responses in Likert Scale categories 1 and 2 (Strongest or Strong), in Figure 1, and - conversely - responses in categories 4 and 5 (Weak or Weakest) in Figure 2.

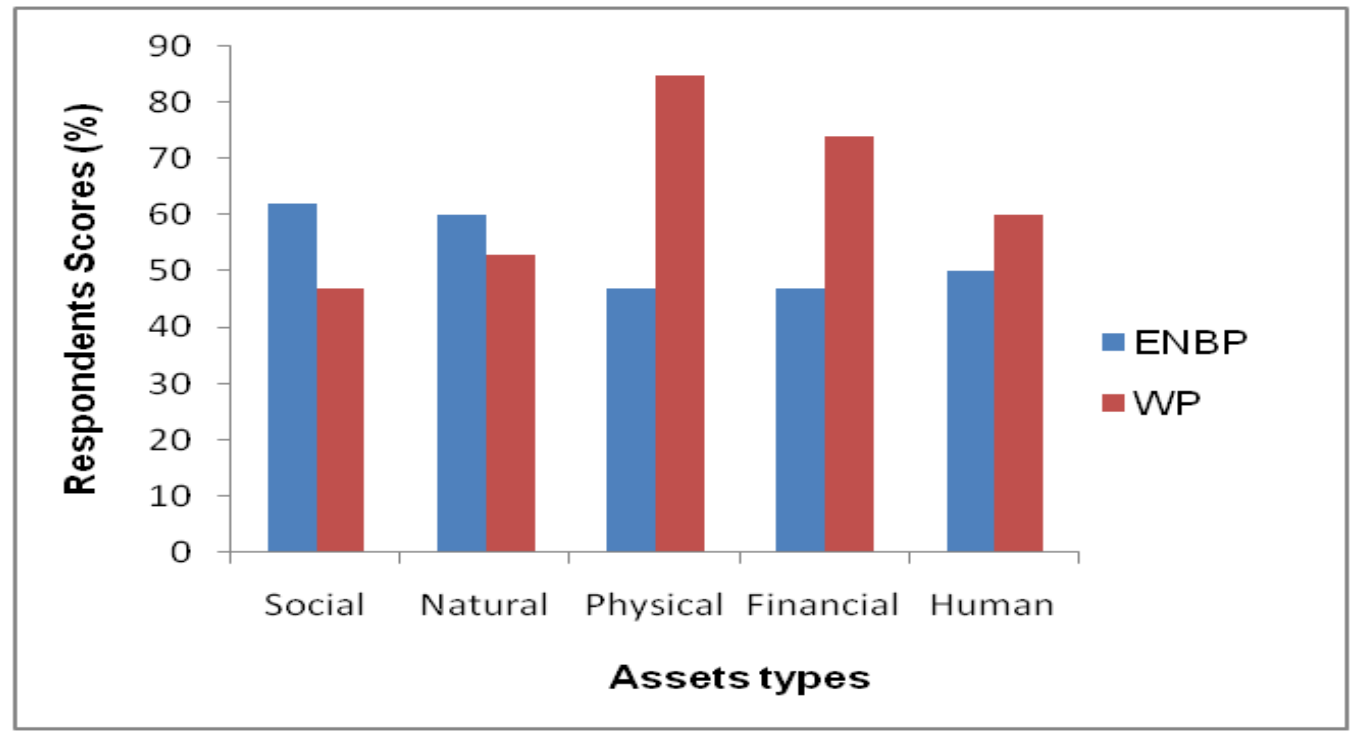

Figure 1: Average proportion of respondents in each of the case study regions who scored each asset as strong or strongest.

As can be seen from Figure 1, social and natural assets are strongest for ENBP study communities (62 and 60 percent respectively) compared to WP (47 and 53 percent respectively). In contrast, financial, human and physical assets were observed to be the strongest (74, 60 and 85 percent respectively) in WP. ENBP have a more similar pattern of asset distribution than does WP. In this sense, ENBP has a more balanced distribution of assets across the different classes. 


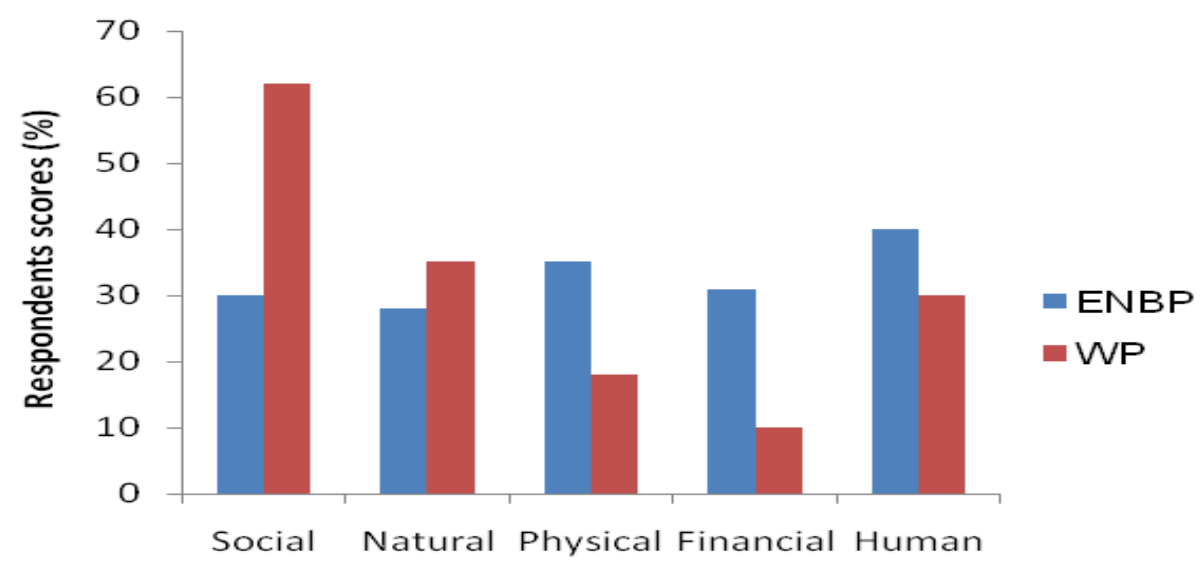

Assets types

Figure 2: Average proportion of respondents in each of the case study regions who scored each asset as weak or weakest.

Figure 2 presents the average proportion of respondents who assessed each asset-base as weak or weakest in each study region. These results are largely the converse of those discussed in Figure 1. ENBP respondents believed that assets class of human (40 percent), was assessed to be weakest; compared to WP (30 percent). The next weakest assets recorded in ENBP were physical, followed by financial, social and natural. In contrast, some 62 percent of WP respondents assessed their social assets to be weakest. The next weakest assets for WP were natural, followed by human. ENBP responses were generally intermediate between those of the assets found in WP.

\subsection{Development outcomes in terms of stability and prosperity}

This section presents the results of the research in response to research question 2 , on communities' stability and prosperity. The discussion explores how and why the predominant form of natural resource development projects in each region has influenced the stability and prosperity of development affected communities. Figure 3 provides an overview of the findings and illustrates the differences between the case study areas. These variations are further discussed in the discussion section 6.3. The analysis was done by using the thematic network process congregating evolving themes as shown in Figure 3.

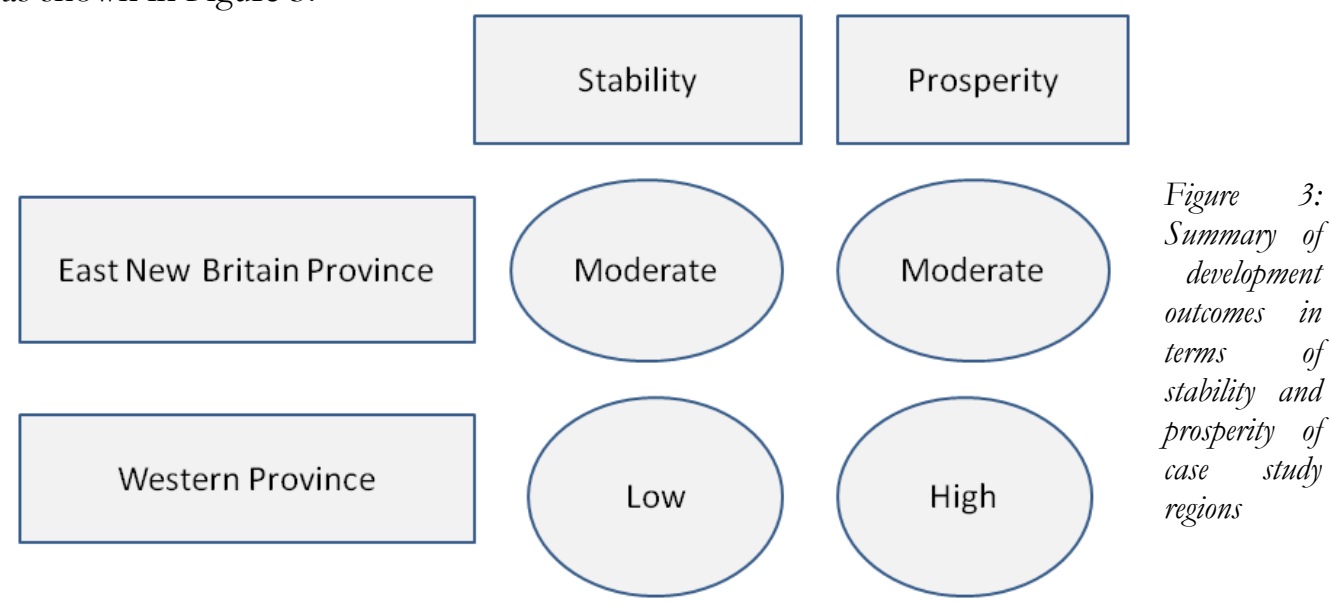


From the diagram above we can see that the East New Britain Province (ENBP) communities recorded balanced and moderate levels of stability and prosperity than the Western Province (WP) communities. In contrast to ENBP communities, WP experienced low of stability and high levels of prosperity.

\section{Discussion}

This section provides an analysis of the results presented above. Figures 1, 2, and 3 provide an overview of the principal study findings in these terms, and illustrate the clear differences between the case study areas.

\subsection{Case study resource projects}

The KOPDP is an agricultural cash crop development project established in 2008. It involves developing plots of land for planting oil palm. Oil palm is considered the best alternative export crop for the province. The project's aim is to generate economic opportunities for the people and the province. The project is yet to deliver anticipated tangible benefits to the communities apart from some initial royalty payments to the landowners of Liaga community. The OTML project is a world-scale gold and copper mine located in the Star Mountains area of Western Province. It is the nation's first major post-independence mining operation, developed as part of a national strategy to generate revenue for the state and create employment opportunities for its people (Kepore and Imbun 2010). Its contribution to PNG is profound, with 25\% of export earnings, 15\% of GDP and 20\% of tax receipts in 2005 (OTML, 2006).

\subsection{Livelihood asset bases in the case study regions}

In terms of livelihoods assets-bases in each study regions. The study demonstrated that the scale and pace of development and type of the resource projects had significant impacts on the type and level of assets bases in the each study communities. These were evident in the five components of the Sustainable Livelihood Framework. For example, the case in WP was dominated by physical assets as their strongest. Their next strongest assets-base was financial with 74 percent, followed by human (60 percent) and natural (53 percent) assets; social assets (62 percent) (Figure 2) were seen as the weakest assets. These results are largely consistent across the WP case study communities, who saw physical and financial assets as their strongest assets, with human and natural assets assessed at intermediate levels. Social assets were seen as weakest. In contrast the case in ENBP has a more balanced distribution of assets across the different classes, although; human assets recorded to be their weakest at 40 percent. These results further implied that high levels of financial and physical assets in WP have been influenced by the fast and robust development intervention of the Ok Tedi mining project and the benefits that came with the project. These were demonstrated by better and improved opportunities in terms of well-maintained roads and infrastructure, huge compensations and royalties payments to landowners than those found in ENBP. The weak assets (social, human and natural) in WP are consistent with other observations made by (Mulung, 2012) that more social and environmental issues were widespread amongst the communities. Thus, the study suggested that increased social conflicts were 
direct results of increased benefits and compensation payments provided by Ok Tedi project to the communities and the unequal sharing of these benefits. As communities competed for these benefits, differences were created amongst the communities about who should get what and how much they should get from the increased compensation and royalties payments. Whilst the observations in ENBP suggested that the five assets bases were moderate and consistent amongst the communities. This simply was due to the modest development opportunities came with the slow and medium agriculture development projects. This further implied that improved and more sustainable development outcomes were favorable in modest agriculture development projects such as the oil palm project in this study. In a similar way robust mining project brought huge benefits but the recipients of the benefits have to use them wisely and convert these benefits into other long term sustainable projects for life after mine.

\subsection{Impacts of development outcomes on stability and prosperity}

The stability and prosperity in the each study communities varied across the region. As illustrated in Figure 3, the ENBP communities experienced moderate levels of stability and prosperity from their agriculture-based development. One reason for this is that the century-long history of both plantation and smallholder agriculture-based development in ENBP has allowed the majority of households to build modest levels of financial, social, physical and human assets. The moderate stability and prosperity in ENBP is also attributed to the early experiences these communities had with various modern governance systems such as community governments. The early government system helped to facilitate the establishment of community-level assets, principally public infrastructure such as roads, hospitals, schools and community halls (Liu, 2010; ENBPG, 2009).

The second reason is that the relatively moderate-high levels of public infrastructure and assets provide all community members with access to these facilities. The history of community-based ownership and use of community assets also meant a high level of individual investment in these resources, and of social capital. This in turn has fostered greater prosperity, in a virtuous cycle, which has lessened the competition within communities over development outcomes. This was consistent with the results presented in Figures 1 and 2, on the current asset-bases of the communities. ENBP, when compared to WP, has better access to public infrastructure services and markets as it has better road networks, transport, health and education.

The third reason that helped stability and prosperity is the communal ownership, and as a result, attitudes to public properties in ENBP communities. Communities have the capability to invest in community-based facilities, including public infrastructure. This can be attributed to the strong and stable social and cultural interactions within the communities, and also to their ability to adapt. They are willing to accept modern concepts, having been introduced to them earlier than in WP, providing a basis for community members to see and value such facilities from a broader community perspective rather than simply in individualized terms. These observations and those of Martin (2013) on traditional trades such as 'sande sande', depict their community-oriented behaviors. This was exemplified by the weekly Mande kivung (compulsory government day) program for community services. The Mande kivung program requires people to do 
community works, including maintenance of community facilities such as cemeteries, churches, schools, markets and other related activities as specified in their community government rules. This ensures that these facilities are maintained and sustained for future use, demonstrating collective long term ownership. This contrasts with the situation described for WP, where community-oriented public infrastructure facilities are effectively 'owned' by a few individuals, leading -amongst other things - to the deteriorating conditions of the facilities and services. For example, a community based public motor vehicle (PMV) bought for the community, using the community development funds, later became the personal property of the community leaders.

Another factor that has contributed to the moderate stability and prosperity in ENBP, particularly in the case of Nabata community, is the matriarchal social structure. Unlike the patriarchal communities in WP and in parts of ENBP, the Nabata (one of the case study) community is predominantly matriarchal, and it is the women who organize meetings and make the decisions. As observed in this community, women's roles in leading and making decisions is based on the cultural aspects of their community which vests ownership rights for land and properties to female descendants. This community promotes women's participation in development processes. This also means that the stability and prosperity of these communities is partly attributed to women's participation and making decisions on behalf of their community. This was manifested in the moderate levels of success in stability and prosperity in ENBP compared to WP communities. In comparison to Nabata and Liaga both communities in ENBP, Nabata residents had various sources of income opportunities. Apart from cash crops (cocoa and coconut), their matriarchal-linked trade activities such as sande sande and tiptip systems made significant contributions to household income for this community. This suggested that there were a range of factors that contributed to both stability and prosperity in this region compared to the other region.

In contrast to ENBP communities, WP communities are relativity prosperous but socially unstable. These communities are being impacted by, and are beneficiaries of, a major mining development. They are characterized by relatively high levels of physical and financial capital. A significant amount of money was earned and spent per household on foods and other items in these communities. Both low subsistence food production systems, high cash economy and livelihood strategies observed in WP also characterize the high dependency of these communities on financial and physical assets. Although aggregate levels of community prosperity were high, low levels of community stability reflected low levels of social capital, as traditionally integrated clans and tribes split and competed for funding that lead to social conflicts, disputes and confrontations, which often turn to violence. The low level of stability in these communities can be attributed, at least in part, to unequal sharing of proceeds and benefits from the mining-based development. However, the region's weak, unstructured and fragmented traditional social institutions also contribute, causing conflicts to escalate without traditional mechanisms to resolve them. This was reflected in the semi-nomadic lifestyle of these communities, and relatively individualized asset ownership only by few people. 


\section{Conclusion}

In conclusion, the study suggests that, impacts of natural resource-based development projects on community livelihoods and stability and prosperity varied across the two study regions. These were evident in the presence of types and levels of livelihoods asset-bases and the development outcomes in terms of stability and prosperity found in the two regions. Overall, these results indicate that, the two study regions had varied levels of livelihoods assets-bases, stability and prosperity in their communities. The level of livelihood assets-bases, stability and prosperity were influenced by the type of resource project (i.e. huge mining project and intermediate project). The length and history of development also contribute to the development outcomes and livelihood assets in the communities. Moreover, the scale and phase of development further added to the impact of development outcomes in the communities. Thus, understanding of impacts of natural resource-based development projects are fundamental to realizing the opportunities and addressing the challenges faced by rural communities (particularly the landowners) engaging with resource projects in PNG; it is also being shaped by such developments. It is fundamentally important to understand the impacts and challenges associated with resources projects and the livelihoods assetbases, prosperity and stability, and particularly those most relevant to the land owning communities, and to design policies and other interventions that build and support the capacity of communities to respond to these opportunities and challenges. However, this also requires a better understanding of the relationships between modern and traditional modes of development in the PNG context, of associated land-based resources development projects and their capacity to adapt to evolving circumstances, and the of implications for policy and resource development interventions. What do these findings mean? It simply meant that to deliver both improve levels of livelihood assets-bases, prosperity and stability needs, more emphasis on agriculture projects as it is a stable and modestly growing sector that can increase and sustain communities livelihoods in the long run. Whilst, the mining projects are robust that come with huge development benefits and has the potential to improve livelihoods in big-way. At the same time, the likelihood of tearing communities apart is high. Thus, there are opportunities that exist in such projects and similar ones in future. It is up to the concerned land/resource owners to convert these huge benefits into tangible and sustainable development outcomes for now and for future. Further research is required to better understand the impacts of resource-based projects on development outcomes in multiple development projects; that involve comparison of different but fully operational resource development projects in; (1) a single sector across the country, and (2) different sectors in the same region (s) of PNG.

\section{Acknowledgements}

This work was funded by ACIAR, under John Allwright Scholarship Program at the Australian National University, Australia. The author also acknowledges the contributions of Professor Peter Kanowski at the Australian National University for the motivation, mentorship and reviews in having this paper for publication. At the Australian National University thanks also go to Dr. Lorrae Van Kerkoff, Dr. Hartmut 
Holzknecht, Dr. Lyndall Bull, and Dr. Michael Blyth for their valuable contributions, directions and guidance throughout this study.

\section{References}

Anderson, T. (2015). Land and Livelihoods in Papua New Guinea. Australian Scholarly Publishing, Melbourne.

Attride-Stirling, J. (2001). Thematic networks: an analytic tool for qualitative research, Qualitative Research, 1 (3): 385-405, Sage Publications, London, Thousand Oaks, CA and New Delhi.

AusAID. (2006). Papua New Guinea development challenges, Pacific Islands Development Program, Retrived 27 January, 2010, From: www. ausaid.gov.au/country/papua.cfm.

Banks, G. (2003). Landowner Equity in PNG's Minerals Setcor: Review and Policy issues. , Natural Resource Forum, 27(3): 223-234. Retrived 25 November, 2012, from www.onlinelibrary.wiley.com/journal

Banks, G. (2008). Understanding 'resource' conflicts in Papua New Guinea, Asia Pacific Viewpoint, 49: 23-34, Victoria University, New Zealand.

Bourke, R. M. and Harwood, T. (2009). Food and Agriculture in Papua New Guinea. ANU ePress, Canberra. 638 pp.

Chambers, R. and Conway, G. (1991). Sustainable Rural Livelihoods: Practical Concepts for the 21st Century, Institute of Development Studies, IDS, Discussion Paper, no. 296, Retrived 24 February, 2011. From www.smallstock.info.

DFID, (1999). Sustainable Livelihoods Guidance Sheets, The Livelihoods Framework. Department for International Development, UK, Retrived 23 February 2011; From http://www.eldis.org/vfile/upload/1/document/0901/section2.pdf.

ENBPG, (2009). Gazelle District Development Plan: Gazelle ikirap, 1(1). Rabaul, Papua New Guinea.

GoPNG, (2011). National Census 2011, Port Moresby.

Jackson, R. (2002). Capacity Building in Papua New Guinea for Community Maintenance During and After Mine Closure. Mining, Minerals and Sustainable Development Briefing. London, International Institute for Environment and Development. 181. British.

Kepore, K., and Imbun, B. (2011). Mining and Stakeholder Engagement Discourse in a Papua New Guinea Mine, Corporate Social Responsibility and Environmental Management 18(4): 220-233.

Liu, M. S. (2010). Livelihood dynamics, Lihir Islands, Papua New Guinea. Unpublished PhD thesis, Lincoln University, Christchurch.

Martin, K. (2013). The Death of the Big Men and the rise of the bigshots - Custom and conflict in East New Britain. Berghahn Books, New York.256 pp.

Mulung, K. (2012). Livelihoods and land-use choices of Papua New Guinean Landowners, and implications for decisions relevant to commercial tree growing. Unpublished $\mathrm{PhD}$ thesis. Australian National University, Canberra.

Ostrom, E. (2009). A general Framework for Analysing Sustainability of Social Ecological, Science, 325, (5939): 419-422

OTML, (2006). Annual Review, OTML Media, Tabubil, Papua New Guinea

Scambary, B. (2013). My Country, Mine Country, Indigenous people, mining and development contestation in remote Australia, ANU Press, Australian National University, Canberra.

Uebersax J. S. (2006).Likert scales: dispelling the confusion. Statistical Methods for Rater Agreement. May, 2018. Retrieved from: http://john-uebersax.com/stat/likert.htm.

Yemiru, T., Roos, A., Campbell, B. M. and Bohlin, F. (2010). Forest incomes and poverty alleviation under participatory forest management in the Bale Highlands, Southern Ethiopia, International Forestry Review, 12 (1): 66-77.

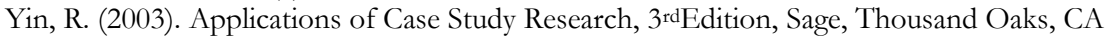


